\title{
PEMBUATAN RESIN PHENOL FORMALDEHID TERHADAP APLIKASINYA SEBAGAI VERNIS
}

\author{
Nur Rokhati ${ }^{*}$ dan Aji Prasetyaningrum \\ Jurusan Teknik Kimia Fakultas Teknik UNDIP Semarang \\ Jl. Prof. Soedarto, SH, Tembalang, Semarang 50239, Telp.(024)7460058 \\ ${ }^{*}$ Penulis korespondensi: nur_r81@tekim.ft.undip.ac.id
}

\begin{abstract}
Abstrak
Phenol formaldehid termasuk kelompok resin sintetis yang dihasilkan dari reaksi polimerisasi antara phenol dengan formaldehid. Ada dua jenis resin phenol formaldehid yaitu : novolak yang bersifat termoplast dan resol yang bersifat termoset. Phenol formaldehid dapat diaplikasikan sebagai vernis karena dapat membentuk lapisan film yang kering.Penelitian dilakukan dengan mereaksikan phenol dan formaldehid dengan $p H$ dan perbandingan mol bervariasi. Jenis novolak dibuat pada suasana asam dengan penambahan $\mathrm{HCl}$, suhu $90^{\circ} \mathrm{C}$, dan waktu reaksi 5 jam, sedangkan jenis resol dibuat pada suasana basa dengan penambahan $\mathrm{NaOH}$, suhu $80^{\circ} \mathrm{C}$ dan waktu reaksi 3 jam. Hasil resin phenol formaldehid diaplikasikan sebagai vernis pada kayu jati. Hasil penelitian menunjukkan bahwa dengan bertambahnya $\mathrm{pH}$ dan perbandingan reaktan, waktu kering semakin lama. Kondisi optimum jenis novolak diperoleh pada $\mathrm{pH}$ 2,5 dan perbandingan reaktan $1: 0,8$, sedangkan untuk jenis resol dicapai pada pH 10 dan perbandingan mol reaktan 1 : 2. Aplikasi jenis novolak sebagai vernis kayu menghasilkan warna yang lebih cerah (tingkat gloss tinggi) dibanding dengan jenis resol
\end{abstract}

Kata kunci : phenol, formaldehid, resin, vernis

\begin{abstract}
Phenol formaldehyde is a group of synthetic resin that is resulted from the reaction of polymerisation between phenol and formaldehyde. They are two kind of resin phenol-formaldehyde, they are novolacthat has thermoplastic character and resole has termoset character. Phenol-formaldehyde can be applicated as varnish because it can form dry film coating.The research is done by the reaction of phenol and formaldehyde with $\mathrm{pH}$ and the comparison of mole variation. This novolac is made in bases acids condition with $\mathrm{HCl}$ additional, $90^{\circ} \mathrm{C}$ temperature, and 5 hours time reaction, whereas resole classification is made in bases condition added $\mathrm{NaOH}, 80^{\circ} \mathrm{C}$ temperature and 3 hours time reaction. The results of resin phenol formaldehyde are applicated as varnish in the teak and mahogany. The result of research indicated that by $\mathrm{pH}$ increasing and the comparison of reactant, the timing dry is longer. The optimum condition of novolac is obtained on $\mathrm{pH} \mathrm{2,5}$ and the comparison reactant 1:0,8, whereas for resole $i$ on $\mathrm{pH} 10$ and comparison of mole reactant 1:2. the application of novolac as wood varnish result brighter colour (high gloss level) than resole, and also the result of teak varnish is better than mahagony wood.
\end{abstract}

Key words: phenol, formaldehyde, resin, varnish

\section{PENDAHULUAN}

Phenol formaldehid merupakan resin sintetis yang pertama kali digunakan secara komersial baik dalam industri plastik maupun cat (surface coating). Phenol formaldehid dihasilkan dari reaksi polimerisasi antara phenol dan formaldehid. Reaksi terjadi antara phenol pada posisi ortho maupun para dengan formaldehid untuk membentuk rantai yang crosslinking dan pada akhirnya akan membentuk jaringan tiga dimensi (Hesse, 1991).
Salah satu aplikasi dari resin phenol formaldehid adalah untuk vernis. Vernis adalah bahan pelapis akhir yang tidak berwarna (clear unpigmented coating). Istilah vernis digunakan untuk kelompok cairan jernih yang memiliki viskositas $2-3$ poise, yang bila diaplikasikan akan membentuk lapisan film tipis yang kering dan bersifat gloss (glossy film). Proses pengeringan pada vernis dapat melalui penguapan (evaporasi) dari solvent, oksidasi dengan udara, dan polimerisasi sejumlah unsur yang terkandung dalam vernis. Hasil akhir dari vernis adalah 
lapisan film transparan yang memperlihatkan tekstur bahan yang dilapisi (Martens, 1967).

Perkembangan phenol formaldehid untuk aplikasi vernis dan lacquer telah mampu menyaingi produk melamin formaldehid karena harganya yang lebih murah. Selain itu, hasil aplikasinya dapat memunculkan jenis vernis dan lacquer yang berwarna sedangkan melamin formaldehid tidak berwarna sehingga bila diinginkan hasil aplikasi yang berwarna tidak perlu penambahan zat warna. Produk phenol formaldehid ada yang memberikan warna jernih kekuning-kuningan tetapi ada juga yang kecoklatan sampai kemerah-merahan.

Berdasarkan perbandingan mol reaktan dan jenis katalis yang digunakan, resin phenol formaldehid dibagi menjadi 2 jenis yaitu novolak dan resol. Resol merupakan hasil reaksi antara phenol dengan formaldehid ekses oleh adanya katalis basa. Jenis katalis basa yang sering digunakan adalah natrium hidroksida dan ammonium hidroksida pada $\mathrm{pH}=8-11$. Produk phenol formaldehid yang dihasilkan dengan katalis natrium hidroksida akan mempunyai sifat larut dalam air dan apabila katalis yang digunakan ammonium hidroksida akan memberikan sifat tidak larut dalam air yang dikarenakan terbentuk bis dan tris hydroksylbenzylamin (Martin, 1956).

Novolak merupakan hasil reaksi antara phenol ekses dengan formaldehid oleh adanya katalis asam. Jenis katalis asam yang sering digunakan adalah asam sulfat, asam klorida, dan asam oksalat dengan konsentrasi rendah. Hasil reaksi akan membentuk produk yang termoplast dengan berat molekul 500 900. Agar novolak menjadi bersifat termoset maka membutuhkan pemanasan dan penambahan crosslinking agent (Frisch, 1967).

Tahap reaksi dalam pembentukan novolak tersaji pada gambar 1 dan 2 .

Pada novolak, reaksi polikondensasi dapat berlangsung sempurna sampai membentuk rantai dengan struktur methylene link dan phenol terminate tanpa adanya gugus fungsional dan tidak dapat cure dengan sendirinya. Pada suasana asam, raeksi kondensasi (pembentukan jembatan methylene) berjalan cepat dibanding pembentukan gugus methylol (Hesse, 1991).

Tahap reaksi dalam pembentukan novolak, meliputi :

a. Reaksi Adisi (Methylolasi)

Pada tahap pertama, phenol dan formaldehid akan bereaksi membentuk monomethylol phenol.<smiles>Oc1ccccc1</smiles>

Phenol

$$
+\mathrm{CH}_{2} \mathrm{O}
$$

Formaldehid

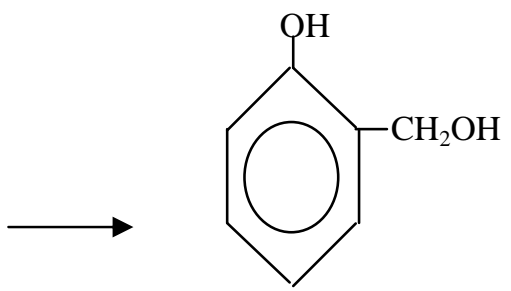

Monomethylol phenol

Gambar 1. Reaksi Methylolasi

b. Reaksi Kondensasi Polimerisasi (Methylenasi)

Pada tahap ini, gugus methylol akan bereaksi dengan phenol membentuk jembatan methylene dan air.<smiles>OCc1ccccc1O</smiles><smiles>Oc1ccccc1</smiles>

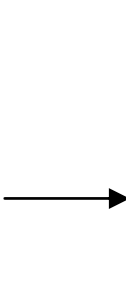<smiles>Oc1ccccc1Cc1ccccc1O</smiles> 
Tahap reaksi pembentukan resol, meliputi :

a. Reaksi Adisi (Methylolasi)

Pada tahap pertama, phenol dan formaldehid akan bereaksi secara adisi membentuk monomethylol phenol.<smiles>Oc1ccccc1</smiles>

Phenol

\section{$+\mathrm{CH}_{2} \mathrm{O}$}

Formaldehid<smiles>OCc1ccccc1O</smiles>

Monomethylol phenol

Pada monomethylol phenol ini masih ada 2 gugus reaktif yang dapat bereaksi lagi dengan formaldehid menjadi dimethylol phenol.<smiles>OCc1ccccc1O</smiles>

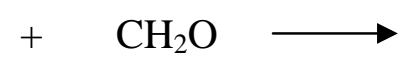

Formaldehid<smiles>OCc1ccc(O)c(CO)c1</smiles>

Dimethylol phenol

Monomethylol phenol dan pada akhirnya membentuk trimethylol phenol.<smiles>OCc1ccc(O)c(CO)c1</smiles>

Dimethylol phenol

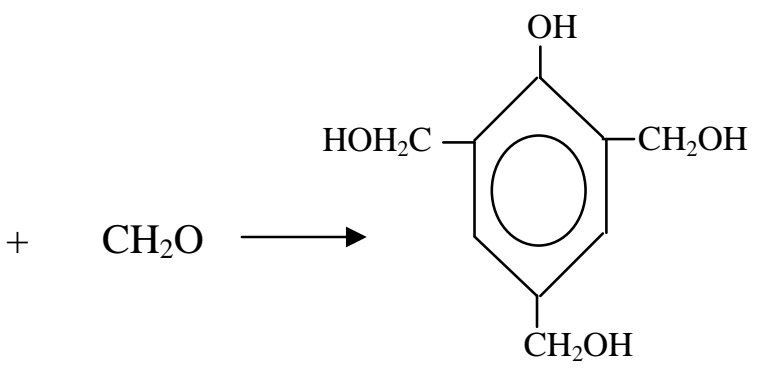

Formaldehid
Trimethylol phenol

b. Reaksi Kondensasi Polimerisasi.<smiles>Cc1cc(C(=O)CO)ccc1CO[C@H](CO)c1cccc(CO)c1O</smiles><smiles>OCc1ccccc1COc1cccc(Cc2cccc(CO)c2O)c1O</smiles> 
Monomer dan dimer tersebut akan terus bereaksi dan berat molekul dari resin akan meningkat. Resol terbentuk pada suasana basa (Frisch, 1967)

\section{METODE PENELITIAN}

Penelitian dilakukan dengan mereaksikan phenol dan formaldehid dengan perbandingan mol tertentu. Jenis novolak dibuat dengan menggunakan katalis $\mathrm{HCl}$ pada $\mathrm{pH}$ tertentu dan suhu $90^{\circ} \mathrm{C}$ selama 5 jam, sedangkan jenis resol dibuat dengan menggunakan katalis $\mathrm{NaOH}$ pada $\mathrm{pH}$ tertentu dan suhu $80^{\circ} \mathrm{C}$ selama 3 jam. Hasil reaksi (resin) dianginanginkan dalam cawan porselin sampai viskous.

Aplikasi resin jenis resol dilakukan dengan melarutkan resin dalam solvent etanol kemudian dikuaskan pada kayu sampai diperoleh lapisan film yang kering. Aplikasi resin jenis novolak dilakukan dengan memanaskan resin padat dan hexamine sampai meleleh kemudian dilarutkan dalam solven etanol dan dikuaskan pada kayu.

Analisa yang dilakukan meliputi waktu kering, tingkat gloss (menggunakan glossmeter), dan warna kayu setelah divernis.

\section{HASIL DAN PEMBAHASAN}

Besarnya $\mathrm{pH}$ dalam reaksi akan mempengaruhi kecepatan dan waktu reaksi pembentukan polimer. Pada jenis novolak, reaksi berlangsung pada suasana asam. Pada suasana asam, reaksi addisi yaitu pembentukan gugus methylol akan berjalan lambat sedangkan reaksi kondensasi yaitu pembentukan jembatan methylen berjalan cepat sehingga produk yang terbentuk bersifat termoplastis.

Dari data pengamatan (tabel 1) dapat dilihat bahwa dengan semakin tinggi $\mathrm{pH}$ reaksi, waktu kering vernis semakin lama. Dengan naiknya $\mathrm{pH}$ maka kecepatan reaksi kondensasi semakin lambat, semakin naik pH maka rantai yang dibentuk semakin bercabang sehingga BM polimer bertambah besar. Perbandingan reaktan (rasio mol phenol : formaldehid) akan berpengaruh pada properties produk dan struktur polimer yang dihasilkan.

Tabel 1 juga menunjukkan bahwa semakin tinggi perbandingan reaktan (P:F), waktu kering vernis semakin lama. Semakin tinggi perbandingan P:F maka struktur rantai yang dibentuk semakin kompleks (mulai dari short chain polimers hingga high cross-linked polymers). Semakin besar BM senyawa resin yang dihasilkan, mengakibatkan waktu kering semakin lama. Karena rasio Formaldehid kurang dari satu mol per mol phenol maka walaupun mempunyai fungsionalitas yang cukup namun tidak mampu untuk membentuk produk yang termoset tetapi membentuk produk yang termoplast dengan berat molekul 500900. Agar novolak menjadi bersifat termoset maka dibutuhkan pemanasan dan penambahan crosslinking agent (Frisch, 1967).

Pada jenis resol, reaksi berlangsung pada suasana basa. Pada suasana basa reaksi addisi berjalan dengan cepat sedangkan reaksi kondensasi (pembentukan jembatan methylen) berjalan lambat sehingga produk yang terbentuk bersifat termoset. Tabel 2 menunjukkan bahwa pengaruh $\mathrm{pH}$ dan perbandingan reaktan terhadap waktu kering vernis tidak berbeda dengan yang terjadi pada jenis novolak. Namun waktu kering vernis jenis resol lebih cepat dibanding dengan jenis novolak, karena resin jenis novolak mempunyai sifat termoplast, sedangkan resol mempunyai sifat termoset.

Tabel 1.Hubungan $\mathrm{pH}$ dan perbandingan reaktan terhadap waktu kering (Jenis novolak)

\begin{tabular}{cccccc}
\hline \multirow{2}{*}{$\mathrm{pH}$} & \multicolumn{5}{c}{ Waktu kering (jam) } \\
\cline { 2 - 6 } & $\mathrm{P}: \mathrm{F}=1: 0,5$ & $\mathrm{P}: \mathrm{F}=1: 0,75$ & $\mathrm{P}: \mathrm{F}=1: 0,8$ & $\mathrm{P}: \mathrm{F}=1: 0,85$ & $\mathrm{P}: \mathrm{F}=1: 0,9$ \\
\hline 1 & 1.5 & 2.5 & 2.25 & 4 & 5.5 \\
2 & 1.5 & 3 & 4 & 12 & 24 \\
2,5 & 2 & 4 & 5.25 & 12 & 48 \\
3 & 4,25 & 5 & 16 & 24 & 72 \\
4 & 24 & 24 & 24 & 48 & 72 \\
\hline
\end{tabular}

Keterangan : $\mathrm{P}: \mathrm{F}=$ perbandingan mol Phenol : Formaldehid

Tabel 2.Hubungan $\mathrm{pH}$ dan perbandingan reaktan terhadap waktu kering (Jenis resol)

\begin{tabular}{cccccc}
\hline \multirow{2}{*}{$\mathrm{pH}$} & \multicolumn{5}{c}{ Waktu kering (jam) } \\
\cline { 2 - 5 } & $\mathrm{P}: \mathrm{F}=1: 1,25$ & $\mathrm{P}: \mathrm{F}=1: 1,5$ & $\mathrm{P}: \mathrm{F}=1: 2$ & $\mathrm{P}: \mathrm{F}=1: 2,5$ & $\mathrm{P}: \mathrm{F}=1: 3$ \\
\hline 9 & 0.5 & 0.75 & 1 & 1.25 & 1.5 \\
10 & 1 & 1.25 & 1.25 & 1.75 & 1.75 \\
11 & 1.5 & 1.67 & 1.67 & 2.25 & 2.25 \\
12 & 2.25 & 2.42 & 2.42 & 3.25 & 3.25 \\
13 & 2.5 & 2.87 & 2.87 & 4 & 4 \\
\hline
\end{tabular}


Nilai gloss merupakan pengamatan secara visual hasil refleksi dari permukaan suatu bahan. Semakin tinggi nilai gloss, maka permukaan bahan yang dilapisi akan semakin mengkilap. Oleh karena itu sering kali nilai gloss dapat digunakan untuk menggambarkan kualitas dari vernis. Tabel 3 dan 4 menggambarkan hasil pengukuran gloss dari resin phenol formaldehid yang digunakan sebagai vernis pada kayu jati.

Data hasil penelitian menunjukkan bahwa tingkat gloss tertinggi pada jenis novolak diperoleh pada pH 2,5 (tabel 3), sedangkan pada resol diperoleh pada $\mathrm{pH} 10$ (tabel 4). Pada $\mathrm{pH}$ semakin tinggi, selain formaldehid bereaksi dengan phenol membentuk resin phenol formaldehid, formaldehid juga akan mengadakan reaksi canizzaro menghasilkan asam formiat dan methanol sehingga reaksi polimerisasi akan berjalan lambat dan tingkat gloss menjadi turun. Pengaruh perbandingan reaktan terhadap nilai gloss menunjukkan bahwa nilai gloss tertinggi untuk novolak diperoleh pada perbandingan mol phenol : formaldehid 1:0,8 (tabel 3), sedangkan untuk resol pada perbandingan 1:2 (tabel 4). Nilai gloss novolak lebih tinggi dibanding resol.

Tabel 5 menunjukkan hasil warna kayu jati yang telah divernis dengan vernis jenis novolak dan resol dari berbagai perbandingan phenol dan formaldehid. Vernis jenis resol yang memberikan warna yang lebih tua dibanding dengan vernis jenis novolak.

\section{KESIMPULAN}

Dari penelitian ini dapat disimpulkan bahwa kondisi optimum pada pembuatan phenol formaldehid untuk jenis resol dicapai pada perbandingan mol phenol dengan formaldehid 1:2 dan $\mathrm{pH}$ reaksi 10, sedangkan untuk jenis novolak pada perbandingan 1:0,8 dan $\mathrm{pH}$ reaksi 2,5. Aplikasi jenis novolak sebagai vernis kayu menghasilkan warna yang lebih cerah (tingkat gloss tinggi) dibanding dengan jenis resol. Selain itu penampakan warna vernis untuk resol adalah merah kecoklatan, sedangkan novolak adalah kuning sampai kecoklatan. Untuk itu maka novolak lebih cocok diaplikasikan sebagai vernis dibanding resol.

Tabel 3.Hubungan pH dan perbandingan reaktan terhadap Nilai Gloss (Jenis novolak)

\begin{tabular}{cccccc}
\hline \multirow{2}{*}{$\mathrm{pH}$} & \multicolumn{5}{c}{ Nilai Gloss (\%) } \\
\cline { 2 - 5 } & $\mathrm{P}: \mathrm{F}=1: 0,5$ & $\mathrm{P}: \mathrm{F}=1: 0,75$ & $\mathrm{P}: \mathrm{F}=1: 0,8$ & $\mathrm{P}: \mathrm{F}=1: 0,85$ & $\mathrm{P}: \mathrm{F}=1: 0,9$ \\
\hline 1 & 52,7 & 60,5 & 73,1 & 60 & 60 \\
2 & 60,4 & 71 & 75 & 70,5 & 63 \\
2,5 & 67,6 & 70,5 & 78,4 & 64,7 & 63 \\
3 & 60,1 & 58,5 & 63,5 & 54,8 & 57,2 \\
4 & 43,3 & 50,5 & 50 & 48,1 & 45 \\
\hline
\end{tabular}

Tabel 4.Hubungan pH dan perbandingan reaktan terhadap Nilai Gloss (Jenis resol)

\begin{tabular}{cccccc}
\hline \multirow{2}{*}{$\mathrm{pH}$} & \multicolumn{5}{c}{ Nilai Gloss (\%) } \\
\cline { 2 - 6 } & $\mathrm{P}: \mathrm{F}=1: 1,25$ & $\mathrm{P}: \mathrm{F}=1: 1,5$ & $\mathrm{P}: \mathrm{F}=1: 2$ & $\mathrm{P}: \mathrm{F}=1: 2,5$ & $\mathrm{P}: \mathrm{F}=1: 3$ \\
\hline 9 & 7,5 & 8,5 & 21,5 & 15 & 6,8 \\
10 & 8 & 12 & 26,6 & 18,8 & 7 \\
11 & 6 & 5,6 & 12 & 7,3 & 4,6 \\
12 & 3,9 & 3,4 & 9,5 & 4,7 & 2,5 \\
13 & 3 & 3,2 & 8,6 & 2,7 & 2 \\
\hline
\end{tabular}

Tabel 5. Perbandingan P:F terhadap warna vernis

\begin{tabular}{cccc}
\hline \multicolumn{2}{c}{ Resol } & & Novolak \\
\hline $\mathrm{P}: \mathrm{F}$ & Warna & $\mathrm{P}: \mathrm{F}$ & Warna \\
\hline $1: 1,25$ & Merah kecoklatan & $1: 0,5$ & Kuning kecoklatan \\
$1: 1,5$ & Merah kekuningan & $1: 0,75$ & Kuning kecoklatan \\
$1: 2$ & Merah kekuningan & $1: 0,8$ & Kuning kecoklatan \\
$1: 2,5$ & Merah kecoklatan & $1: 0,85$ & Kuning kecoklatan \\
$1: 3$ & Merah kecoklatan & $1: 0,9$ & Kuning kemerahan \\
\hline
\end{tabular}




\section{DAFTAR PUSTAKA}

Billmeyer, F.W., (1962), “Text Book of Polymer Science", Intescience Publishers, a Division of John Wiley and Sons, New York

Charles R. Martens, (1967), “Technology of Paint, Varnishes and Lacquers”, Associated Products The Sherwin Williams Company Cleveland, Ohio
Frisch, K.C., (1967), "Phenolic Resin and Plastics dalam Kirk Othmer Encyclopedia of Chemical Technology”, Vol. 15 Edisi 2, Mei Ya Publication Inc

Hesse, W., (1991), “Phenolic Resin” dalam Ulmann's Encyclopedia of Industrial Chemistry, Vol. 19 Edisi 5, VCH Publishers, New York

Martin, R. W., (1956), “The Chemistry of Phenolic Resins”, John Willey \& Sons Inc, New York 